\title{
Dynamic Assessment for Better Placement: Implications of Vygotsky's ZAD and ZPD
}

\author{
Hessam Agheshteh \\ English Department, Islamic Azad University, Azadshahr Branch, Azadshahr, 49717-67561, Iran \\ E-mail: h_agheshteh@yahoo.com
}

Received: 12-02- 2015

Published: 01-09- 2015

\author{
Accepted: 18-04- 2015
}

doi:10.7575/aiac.ijalel.v.4n.5p.190
Advance Access Published: May 2015

URL: http://dx.doi.org/10.7575/aiac.ijalel.v.4n.5p.190

\begin{abstract}
As argued by Poehner (2008), Dynamic Assessment (DA) can substantially improve our understanding of students' abilities and promote their development at the same time by providing information on both the individuals' Zone of Actual Development (ZAD) and their Zone of Proximal Development (ZPD), and this way helps us avoid overestimates and underestimates of these individuals' abilities. The present study, as a result, was an attempt to investigate the role DA can play in students' placement into appropriate levels and courses of education. For this end, the researchers observed and recorded the placement interviews of four placement teachers in the Iran Language Institute (ILI) and Nashr-e-Zaban. The researchers analyzed the gathered data and found out that the placement teachers dealt more with the students' ZAD than their ZPD. Adopting the Interactionist Model of DA, and believing that "understanding individuals' abilities necessitates intervention" (Poehner, 2008, p. 113), the researchers discussed DA and its key concepts including ZPD, mediation, scaffolding, intervention, the assessment-instruction integration and the role these could play in a better prediction of the students' future performance and emergent abilities. Having discussed DA and its key concepts using some examples from previous placement interviews in a six-hour course, the researchers observed and recorded the placement interviews of the four teachers in the following term. The gathered data were transcribed and interpreted to see if the intervention had an effect on placement teachers' performance of placement interviews. The results showed that placement teachers then relied more on DA and its key concepts as better indicators of students' future performance. The implications are for those teachers who hold placement interviews to adopt a more development-oriented approach and assess the students' both ZAD and ZPD so that they can avoid misplacements into inappropriate levels and courses.
\end{abstract}

Keywords: Dynamic Assessment, placement, ZAD, ZPD

\section{Introduction}

To enter a program, students everywhere are supposed to go through a placement exam by which they are placed into a certain level or course of education. The placement exam can be either written or oral or both. One of the most common complaints in this area of placement is students being placed into lower or higher levels or courses, or to use Vygotsky's (1978, 1986, 1993 ) terminology, students being placed either below their ZPD or above.

In addition, the idea that students can be assigned into a certain level or course of education based on a single performance on a single test at a certain time has been seriously challenged especially by those working in the area of DA (Vygotsky, 1998; McNamara, 1997; Poehner, 2008).

Luria (1961), one of Vygotsky's highly influential coworkers, contrasted 'statistical' approaches to assessment with those of 'dynamic' ones (p. 7). Statistical assessment, as argued by Luria, though rooted in firmly established psychometric principles, inappropriately takes it for granted that an individual's single performance on a test shows a full picture of his or her abilities. Dynamic assessment, on the other hand, holds that a complete picture of an individual's capabilities needs two more pieces of information: the individual's performance with some help granted by someone and the extent to which the individual is able to respond to this help not only to complete the same activity, but also to transfer this mediated performance to other activities. McNamara (1997) voices the same argument proposing that "the presence of assistance" can give teachers some key information on an individual's "potential for growth" and therefore must be incorporated in all assessment procedures and rating scales used to gauge students' abilities (p. 454).

Since DA is deeply rooted in the concept of ZPD, it insists that any assessment procedure that does not take an individual's potential for growth into consideration will be under question. Traditional assessment procedures, deeply concerned with rigorous psychometric principles, hold that any change or any development in the individual's performance during the administration of the test threatens those psychometric principles, especially the reliability of the test which assumes almost consistent scores across different administrations (see Lidz, 1991; Haywood et al., 1990). DA is, however, more concerned with development than measurement and reliability in that sense of the word is not a concern of the DA (Poehner, 2008). 
In brief, Vygotsky (1998), in the light of the concept of ZPD, contended that a person's ZAD which is determined by his or her performance with no assistance "not only does not cover the whole picture of development, but very frequently encompasses only an insignificant part of it" (p. 200). Vygotsky believed that mediation and the individual's ability to benefit from that mediation was absolutely essential for revealing his or her true cognitive ability because it provided insight into the individual's future development.

The present study is intended to see if the Iranian placement teachers are using ZAD, ZPD or both. In case they're concerned more with $\mathrm{ZAD}$ and not $\mathrm{ZPD}$, the researchers will intervene and introduce $\mathrm{DA}$ as a better alternative to assess the students' full potential for learning. The researchers, then, will analyze the data to assess the effects of intervention on placement teachers.

\subsection{Statement of the Problem}

Central to DA, according to Poehner (2008, p. 24), is the belief that "cognitive abilities can only be fully understood by actively promoting their development." Poehner further argues that "the assessment-instruction dualism" is overcome by integrating them according to the principle that" mediated interaction is necessary to understand the range of an individual's functioning but that this interaction simultaneously guides the further development of these abilities" ( $p$. 24). Besides, as Poehner (2008) stresses, according to Vygotsky's microgenesis which is specifically concerned with the issue of development occurring very fast, it is not hard to imagine that even a single session or a single minute in which a mediator (a teacher and/or a peer) and a student mutually build a ZPD can lead to development on the part of the student.

So as discussed above, scaffolding learners offering them assistance and mediation can effectively shed light on their abilities that are developing let it be in a single session of a few minutes. This mediation and scaffolding which is embodied in DA argues that the students' full range of abilities will be both identified and developed if that mediation is provided let it be in a single session.

Based on what has been argued for above, the present study was an attempt to investigate the possible applications of DA for the placement interviews conducted to put students into some specific educational levels and courses. The study specifically sought to see if placement teachers were concerned with both ZAD and ZPD to assess their applicants' abilities or not. The study also examined the possible effects discussing DA and its key ideas for better placement could have on the placement teachers' performance.

\subsection{Research Questions}

Vygotsky (1978) suggested that a child's functioning cannot be fully understood without knowledge of both their ZAD and ZPD. When used for diagnostic purposes, DA should yield information regarding the learner's ability to profit from intervention, the intensity of intervention needed to facilitate the learner's competence, the nature of the processes obstructing more optimal performance, and the types of interventions that show promise for promoting the learner's mastery of the task. This is what Edelenbos and Kubanek-German (2004) have termed "diagnostic competence."

Following Vygotsky, the researchers set to explore the following two questions.

1. Do placement teachers in Iran assess the students' ZAD, ZPD or both?

2. Does intervention help the placement teachers predict students' potential level better using DA?

\subsection{Significance of the Study}

As mentioned elsewhere in the text, one of the most common complaints in placement exams is placing students in either a lower or a higher level or course of education i.e a level or a course below or beyond their ZPD. In either case, the students will face serious learning and development problems. When placed in a level which deals with their ZAD, students will not be able to develop and move ahead. When placed in a level or course which deals with something beyond their ZPD, again students will not be able to benefit from the course. In both cases, the students might be seriously demotivated, lose their interest, and experience a lot of stress and anxiety.

As a result, as stressed by Vygotsky (1978, 1998); McNamara (1997); Poehner (2008), it seems placement teachers need to assess students' both ZAD and ZPD to get a better picture of their full abilities.

By scaffolding performance, which is the case with DA, learners are encouraged to perform at their highest level, which would be expected to decrease their variability and thereby decrease the so-called error of measurement. This is one supporting factor for DA, and there is evidence that DA has this effect (e.g., Guthke, 1982). Furthermore, DA has been documented to provide unique information to tests of intelligence in accounting for the achievement variability, as well as superior prediction of future learning, compared to traditional tests of intelligence (Guthke \& Beckmann, 2000; Lidz, Jepsen, \& Miller, 1997). In fact, there is rapidly accumulating documentation to support the validity and reliability of these procedures (Lidz, 1996; Lidz \& Elliott, 2000a).

Up to the present moment, no study has addressed the issue of placement in the Iranian context. In the light of the implications of DA, the present study will attempt to explore the placement interviews conducted in the Iranian language schools. Each year thousands of students in the country take written placement exams and then go through placement interviews. The study will focus on the second phase of the placement, i.e. the interviews which play a key role in the students' placement into an appropriate level. 
Rooted in Vygotsky's Sociocultural Theory of Mind (SCT, see Lantolf, 2000), DA argues that students' responsiveness to scaffolding, and mediation that tap into their potential level of ability can both reveal and at the same time develop their cognitive functions, functions that will remain undeveloped if the students' potential for learning is not tapped. This is in line with Vygotsky's arguments, according to which, providing appropriate scaffolding and mediation can enable individuals to move beyond their independent performance, which will, in turn, stimulate further development of the individuals' cognitive functions (Vygotsky, 1986, 1998). Thus, DA, besides measuring the students' current level of language ability (their ZPD), strives to explore their potential ability for learning and develop it through appropriate intervention (Sternberg \& Grigorenko, 2002). DA, as argued here, goes beyond what traditional non-DA procedures were after i.e. mere measurement of students' linguistic abilities. It is, in fact, an ongoing, future- and developmentoriented process of mutual collaboration that can show both the teachers and learners the underlying reasons of learners' performance problems and help learners overcome those problems. In other words, DA integrates assessment and instruction not differentiating instructional activities from assessment activities to deal with the students' both ZAD and ZPD.

Thus under conditions of mediation, scaffolding, and mutual collaboration, students may come to reveal some of their potential functions that have not yet been developed but are ready to get internalized as soon as they are tapped. According to Vygotsky $(1986,1998)$, these potential yet undeveloped cognitive functions all belong to the students' ZPD in contrast to their already completely developed cognitive functions that all belong to their ZAD. Whereas the non-DA assessment procedures show us the students' existing abilities already fully developed in the past, the ZPD allows us to evaluate the students' potential ability to benefit from mediations provided by a teacher or a more competent student. This assessment of the students' future potential learning ability may serve as a better indicator of the students' educational needs than the traditional static scores obtained by non-DA assessment procedures. The possible interventions Vygotsky proposes to assess individuals' ZPD include asking leading questions, modeling, demonstrating, giving examples, and so on. However, vygotsky did not present any standardized procedure for the assessment of the individuals' ZPD.

Vygotsky (1956: 446-47, cited in Wertsch, 1985, p. 68) once wrote

Imagine that we have examined two children and have determined that the mental age of both is seven years. This means that both children solve tasks accessible to seven-years old. However, when we attempt to push these children further in carrying out the tests, there turns out to be an essential difference between them. With the help of leading questions, examples, and demonstrations, one of them easily solves test items taken from two years above the child's level of [actual] development. The other solves test items that are only a half-year above his or her level of [actual] development.

For Vygotsky the two children mentioned above are both the same and different, as he points out a bit further in the same passage:

From the point of view of their independent activity they are equivalent, but from the point of view of their immediate potential development they are sharply different. That which the child turns out to be able to do with the help of an adult points us toward the zone of the child's proximal development. This means that with the help of this method, we can take stock not only of today's completed process of development, not only the cycles that are already concluded and done, not only the processes of maturation that are completed; we can also take stock of processes that are now in the state of coming into being, that are only ripening, or only developing. (Vygotsky, 1956: 447-48; cited in Wertsch, 1985, p. 68).

Budoff and Feuerstein (see Lidz, 1987; Poehner, 2008) were the first researchers to fully operationalize educational programs for dynamic assessment of general cognitive functions. Budoff believed that DA was a much better tool to classify students and predict their future development. Feuerstein, too, argued that the main purpose of DA was to discover and actualize the students' inclination toward future cognitive change.

The pioneering research available on placement is Antón (2003), who used the interactionist DA to place students in an advanced university level L2 Spanish program. It is interesting that, in this research study, she does not take the pedagogical implications of DA into consideration; she never talks about the development which takes place during the DA procedures but instead decides to focus on the potential DA can have in giving a more complete picture of learners' abilities, which, according to her, led to more accurate placements in the Spanish L2 program. Antón's study strongly supports the validity of using DA for placements. She demonstrates that DA assessment procedures are superior to nonDA procedures because DA procedures, by scaffolding students to assess their ZPD, show some very significant differences in students' potential learning abilities.

\section{Methodology}

\subsection{Participants}

The participants of the study are four placement teachers currently working in the Iran Language Institute (ILI) and Nashr-e-Zaban. The teachers hold either a BA or an MA in English literature and English language teaching. They have an experience of at least seven years and have taught all of the levels presently being offered in the institutes. As a 
result, they have a good command of the materials and their content and a good intuitive knowledge of what each level is like.

\subsection{Method}

In the placement exam in Iran, the students go through two phases. The first is a written exam consisting of a number of questions which closely correspond to the different levels and courses currently being offered in the institutes. This is mostly designed to assess student's knowledge of English vocabulary and grammar. The second is an interview held mostly immediately after the written exam to check students' oral fluency. Due to institutional limitations, the present study focuses on the second phase of the placement exam i.e. the interview, which plays a key role in students' placement.

Adopting the Interactionist Model of DA, the researchers observed and recorded five of the placement interviews conducted by each placement teacher, transcribed them and interpreted the data. Realizing that the placement teachers were mostly concerned with the students' ZAD and there was almost no development-oriented effort, the researchers intervened discussing the possible applications of DA and its key terms including ZPD, intervention, mediation, scaffolding, and development-centered language testing. The researchers, then, observed and recorded five of the placement interviews conducted the following term to see if the placement teachers performed differently or not, to see if they were better able to keep an eye on both the students' ZAD and ZPD, and to see if they were concerned with measurement and development or only the former. The researchers also conducted a semi-structured interview with the placement teachers to seek their opinions toward the new assessment procedure.

\subsection{Data Analysis}

The gathered data came from observations and interviews which were recorded and transcribed. Using Constant Comparative Method (Ary, Jacobs and Sorensen, 2010), the data were analyzed for traces of interactions dealing with students' ZAD and/or ZPD. To ensure validity, the researchers employed member checks according to which the researcher checks his own interpretations of the data with those of the participants. Member checks can significantly improve the validity of the researchers' interpretations of qualitative data (Ary, Jacobs \& Sorensen, 2010). Any disagreements were put to negotiations.

\section{Findings and discussion}

According to Vygotsky, ZAD refers to the cognitive functions the child is able to perform without any assistance, whereas ZPD refers to those cognitive functions the child is able to perform with the assistance of a more competent collaborator (e.g., parent, teacher, peer). The ZAD represents yesterday, whereas the ZPD represents tomorrow. It is not difficult to understand the relevance of the ZPD for the instructional situation, as it can also be conceptualized as the instructional zone and describes the target of the educational process. Standardized and curriculum-based procedures inform us about the ZAD while DA informs us about the ZPD. An important implication is that we need both (Lidz, 1995). The problem is that we have been overfocused on-one could say, obsessed with-the former (Haywood, Tzuriel, \& Vaught, 1992).

The analysis of early observations of placement interviews recorded, transcribed, and analyzed corroborated what Haywood, Tzuriel, \& Vaught above argued. The placement teachers in the Iranian context were more concerned with yesterday (ZAD) than tomorrow (ZPD). The placement teachers as mediators made very few interventions to scaffold the students being placed to be able to fully tap into their potential for future learning.

Having checked the results of the written exam, one placement teacher, asking a student to look at a picture, said:

$\mathrm{S}: \ldots$

$\mathrm{T}: \mathrm{Ok}$, what is it here?

S: Picture.

T: Full answers, please.

S: It's picture

$\mathrm{T}$ : Ok, what's the man in the picture doing?

S: Ehhh ... he reading

$\mathrm{T}$ : Is he reading a book?

S: No, he eee read a newspaper.

$\mathrm{T}$ : Do you sometimes read a newspaper?

$\mathrm{S}$ : Yes, read newspaper.

$\mathrm{T}: \ldots$.

As is clear from the interactions above, the teacher trying to elicit present progressive and simple present tenses is most concerned with the student's ZAD. He does not make any interventions to see if the student is able to answer if he is provided with a little bit of assistance or not. For example, the teacher asks two questions on present progressive to see if the student is able to use it correctly or not. However, he does not intervene even when he finds out that the student is not able to answer. He does not provide the student with any feedback on his performance, neither implicit nor explicit feedback, to be able to tap into the student's potential for learning from assistance. Here, the placement teacher could 
easily check the student's potential ability to benefit from assistance and see how much assistance he needed to perform the task. In addition, if the teacher had intervened, the student would have left the office with some development besides his (mis) placed level. Development, after all, is what DA is most concerned about be it in a single session.

Another interesting example comes from a teacher interviewing a student who had already studied up to a specific level but had quit the institute for about three terms and now was back and expected to take up where he had left. After greeting and asking a few warm-up questions, the teacher asked:

S: .....

$\mathrm{T}$ : What is a noun clause?

S: Ehhh ...

T: Give a sentence with a noun clause, please.

S: Ehhh ...

$\mathrm{T}$ : What's an adjective clause?

T: You see you don't know what a noun clause is ... what an adjective clause is. How do you want to start with the same level?

S: Well, ehhh ......

$\mathrm{T}: \ldots$.

Here again, the placement teacher who seems to be more concerned with metalanguage than language itself does not intervene to assess the student's ZPD to see how much he can benefit from assistance. The teacher as the mediator could have at least posed his question using a noun clause himself saying "Do you know what a noun clause is?" or "Can you give a sentence which contains a noun clause?" Or he could have intervened giving an example of a noun clause to see if the student can befit from the example and produce some more.

It would have been much better, however, if the teacher focused on language and not metalanguage to be able to elicit some sentences containing either a noun or an adjective clause. The teacher may have followed a conversational patter like the one below.

$\mathrm{T}$ : Do you know where we can find $\mathrm{X}$ ?

S: I don't know.

T: What don't you know?

S: ......

Here if the teacher is concerned with the student's ZAD, he will stop when the student says, "I don't know" believing that noun clauses are not a part of this student's ZAD. A teacher concerned with the students' ZPD, however, will continue intervening and providing the student with some assistance. This is because two students with the same ZAD might have different potentials for future learning (Vygotsky, 1998; Poehner, 2008).

The data is replete with examples of interactions which show the teachers are more concerned with the students' ZAD and not their ZPD. It seems teachers are more concerned with measurement than development. They pay very little attention to the students' potential ability.

Now we will discuss some examples from the interactions between the teachers and students after the researchers discussed DA and its key concepts with the placement teachers in a six-hour session. The examples clearly show that teachers are now concerned with both their students' ZAD and ZPD. The data show, besides assessing the students' $\mathrm{ZAD}$, teachers are also concerned with development let it be in a single session of five to fifteen minutes.

An interesting example comes from a placement teacher interviewing a young girl. After greeting and asking some questions on personal information as a warm-up, the teacher asks the student to look at a picture and then asks a few questions.

S: ...

T: Look at the picture here, please. What are they doing now?

S: They eh ... walking in the park.

T: what are they doing?

S: They eh ... walking in the park.

$\mathrm{T}$ : What ARE they doing?

$\mathrm{S}$ : Oh, they are walking in the park.

$\mathrm{T}$ : Are they eating anything?

S: Yes, they are eating ice cream. 
$\mathrm{T}$ : Are you eating anything right now?

S: No

T: What are you doing?

S: I'm ... I'm talking to you.

$\mathrm{T}: \ldots$

In the example above, it is clear that the teacher is now trying to delve more into the student's ZPD. When the student is not able to answer, he repeats his question as an almost implicit feedback or assistance to indicate that her answer was not correct. When the student is not able to correct herself, the teacher moves to a more explicit feedback and pronounces "are" with a bit of stress on it. Given this, the student corrects herself and gives the correct answer. The teacher asks more questions on present progressive to check if the student can use it consistently correct or not. The student answers all the questions correctly indicating her potential for learning from assisted learning. This students' placement will be clearly different from the placement of the student who is not able to learn from the teachers' scaffolding.

Another example comes from a placement teacher who, having checked simple present and present continuous, moves to the past tense:

S: ...

$\mathrm{T}$ : Well, what time did you get up this morning?

S: Ehhh ... I get up at 7.

T: Please again!

S: Well, I get up at 7.

$\mathrm{T}$ : What time DID you get up this morning?

S: Oh ... yes! I'm sorry. I got up at 7.

$\mathrm{T}$ : What time did you have breakfast?

S: I had breakfast at seven thirty.

T: Did you leave home at eight?

S: Yes! I left home at eight.

T: Are you going to get up at 7 tomorrow too?

S: ...

Here the teacher successfully checking present tenses moves to past tenses. As it is clear from the example above, the student is able to benefit from the teachers' feedback. This students' placement will be definitely different from the placement of a student who is not able to benefit from the teachers' scaffoldind as in the example below:

S: ...

T: and what time did you go to school?

S: I go to school at seven.

T: Again please!

S: I go to school at seven.

T: What time DID you go to school?

S: I going to school at seven.

T: What is the past form of "go"?

S: Oh! I goed to school at seven.

T: No! I we......

S: I ...

T: I WENT to school at seven. And what time did you come back home?

S: ...

Here this student is not able to benefit from the teachers' implicit feedback and the teacher is forced to provide him with the most explicit feedback. The point here is that the teacher provides the student with some scaffolding but the student, unlike the student in the previous example, is not that much able to benefit from the teachers feedback. The first student was not able to use simple past, but when provided with the most implicit feedback, he or she could correct himself or herself. The latter student, however, needed very explicit feedback. If the teacher had not intervened to assess these two 
students' potential, he might have put them in the same level. However, when the teacher intervened by providing feedback, the first student proved his potential to use the missed simple past tense question was completely different from the potential ability of the second student. What is more important is the point that both students added to their knowledge of English, i.e. the placement interview went beyond mere measurement to development.

One main reason teachers see assessment and instruction as two different processes not related to one another, as Poehner (2008) stresses, is the teachers' lack of familiarity with the theory and principles underlying assessment practices. However, as the present study showed, discussing current assessment theories, DA in this study, can fill the gap and help the teachers better assess their students' abilities, both what they have learnt yesterday and what they can learn tomorrow. This will also help them promote their students' development at the same time.

This was also confirmed from the data obtained from semi-structured interviews conducted at the end of the study. After discussing applications of DA in student placement, and after the teachers tried to incorporate the insights from DA, the researchers conducted an interview to seek the placement teachers' opinions regarding placement in the light of DA. The data were recorded, transcribed and analyzed. Two of the themes found were the teachers' emphasis on DA potential to both gauge and promote students' abilities. One teacher said:

I had never thought about it this way, students' current ability and potential ability. I thought I was supposed to assess the students' current level. I believed this could give me sufficient information to put him in an appropriate level. But I think differently now. DA was great. It made me aware of something I had never thought about. You know I could teach my students, too.

Another teacher said:

I had never thought about student learning during placement interviews. I just asked a few questions to gauge the students' present level. I seldom gave any hints. But it's great if we teach something to the students, too. They spend a lot of time and pay a good sum of money for the placement after all. If they learn something, they will leave the session with a positive feeling. We can have a good impression on the students.

\section{Conclusion}

Assessments conducted for placement purposes usually involve very few observations, or even a single observation of performance, serving as the basis for generalizing individuals' probable functioning in the future. For this reason, assessors need to go to great lengths to control for sources of variance in their procedures. One of the most promising assessment theories currently in vogue is that of DA which is based on Vygotskey's Sociocultural Theory of Mind. According to Vygotsky (1956 cited in Wertsch, 1985), from the point of view of their independent activity, the students might be equivalent, but from the point of view of their immediate potential development the same students might be sharply different. This is why placement teachers are strongly required to explore both the students' ZAD and ZPD. For placement purposes, as the present study showed, placement teachers need to focus on both what the students have learnt yesterday and what they are able to do tomorrow. The present study in Iran clearly showed how placement teachers focused mostly on the students' ZAD, and how they were redirected towards checking both the students' ZAD and ZPD to avoid overestimates and underestimates of students' emergent abilities.

\section{References}

Antón, M. (2003). Dynamic assessment of advanced foreign language learners. Paper presented at the American Association of Applied Linguistics, Washington, D.C., March 2003.

Edelenbos, P., \& Kubanek-German, A. (2004). Teacher assessment: the concept of diagnostic competence. Language Testing 21(3): 259-283.

Guthke, J. (1982). The learning test concept - An alternative to the traditional static intelligence test. The German Journal of Psychology 6(4): 306-324.

Haywood, H.C., Brown, A. L., \& Wingenfeld, S. (1990). Dynamic approaches to psychoeducational assessment. School Psychology Review 19: 411-422.

Lantolf, J.P. (Ed.). (2000). Sociocultural theory and second language learning. Oxford: Oxford University Press.

Lidz, C.S. (Ed.). (1987). Dynamic assessment: An interactive approach to evaluating learning potential. New York: The Guilford Press.

Lidz, C.S. (1991). Practitioner's guide to dynamic assessment. New York: Guilford.

Lidz, C.S., \& Elliott, J. G. (2000). Dynamic assessment: Prevailing models and applications. Amsterdam: Elsevier.

Luria, A.R. (1961). Study of the abnormal child. American Journal of Orthopsychiatry: A Journal of Human Behavior 31: $1-16$.

McNamara, T. (1997). "Interaction" in second language performance assessment: whose performance? Applied Linguistics 18: 446-466.

Poehner, M.E. (2008). Dynamic assessment: A Vygotskian approach to understanding and promoting L2 development. New York: Springer. 
Sternberg, R.J., \& Grigorenko, E. L. (2002). Dynamic testing. The nature and measurement of learning potential. Cambridge: Cambridge University Press.

Vygotsky, L.S. (1978). Mind in society: The development of higher psychological processes. Cambridge, MA: Harvard University Press.

Vygotsky, L.S. (1986). Thought and Language. Newly Revised and Edited by A. Kozulin. Cambridge, MA: MIT.

Vygotsky, L.S. (1993). The diagnostics of development and the pedological clinic for difficult children. (J.E. Knox and C.B. Stevens, Trans.). In R.W. Rieber and A.S. Carton (Eds.), The collected works of L.S. Vygotsky. Vol.2. The fundamentals of defectology. Abnormal psychology and learning disabilities. New York: Plenum.

Vygotsky, L.S. (1997). The crisis in psychology. In R.W. Rieber (Ed.), The collected works of L. S. Vygotsky. Vol. 3. Problems of the theory and history of psychology including the chapter on the crisis inpPsychology. New York: Plenum.

Vygotsky, L.S. (1998). The problem of age. In R.W. Rieber (Ed.), The collected works of L. S. Vygotsky. Vol. 5. Child psychology. New York: Plenum.

Wertsch, J.V. (1985). Vygotsky and the social formation of mind. Cambridge, MA: Harvard University Press. 